\title{
OPENNESS, PRIVILEGE, AND OMNISCIENCE
}

\section{CHRISTOPHER HUGHES}

King's College London

\begin{abstract}
According to egalitarians, there is no privileged now-possible history. Egalitarianism seems to provide an attractive way to reconcile openness and omniscience, but, I argue, it does not.
\end{abstract}

Let us say it is ahistorically possible that $p$ if and only if it could have been the case that $p$. And let us say that it is historically possible that $p$ if and only if it could still be the case that $p$ (could even now be the case that $p$ ). My living to 70 is (apparently) a historical possibility, but my dying before 20 is not. Let us say it is historically contingent that $p$ just in case it is historically possible that $p$, and historically possible that it's not the case that $p$. In what follows, unless I explicitly say otherwise, possibility, contingency, and necessity should always be understood historically.

\section{AN ARGUMENT FOR THE INCOMPATIBILITY OF OPENNESS AND OMNISCIENCE}

1. Suppose that for some proposition $\mathrm{p}$, it's contingent whether $\mathrm{p}$.

2. Then for some proposition $\mathrm{p}$, it is only contingently true that $\mathrm{p}$.

3. Where $\mathrm{p}$ is some proposition that is only contingently true, either God accepts that p, or it's not the case that God accepts that p.

4. If God accepts that $\mathrm{p}$, and it's only contingently true that $\mathrm{p}$, then God accepts p, and it's (still) possible that it's not the case that $p$.

5. If God accepts that $p$, and it's still possible that it's not the case that p, then it's (still) possible that: God accepts that p, even though it's not the case that $\mathrm{p}$. 
6. If it's (still) possible that: God accepts that $p$, even though it's not the case that $p$, then it's (still) possible that: God is mistaken to accept that $\mathrm{p}$.

7. If it's (still) possible that God is mistaken to accept that $p$, then it's not the case that God knows that $\mathrm{p}$.

8. So (by (4) -(7)), if God accepts that p, and it's only contingently true that $p$, it's not the case that God knows that $p$.

9. If on the other hand it's not the case that God accepts that p, and it's only contingently true that $p$, then once again it's not the case that God knows that $\mathrm{p}$ (it can't be true that someone knows that $\mathrm{p}$, if it's not even true that that someone accepts that $\mathrm{p}$ ).

10. So (by (3), (8), and (9)) for some true contingent proposition p, it's not the case that God knows that $\mathrm{p}$.

11. If for some true contingent proposition $\mathrm{p}$, it's not the case that God knows that $\mathrm{p}$, then it's not the case that there is an omniscient God.

12. So ((by (1) - (11)) if there are contingent propositions, there is no omniscient God: the existence of an open future precludes the existence of an omniscient God.

Elaborately formulated arguments have their virtues, but elaborateness of formulation can make it harder to see what the core of an argument is. So it may be helpful to reformulate (the gist of) the above argument as follows:

Say that an epistemic subject risks error with respect to a proposition when there is a (still) possible future in which it turns out that $\mathrm{s} / \mathrm{he}$ is in error with respect to that proposition. It seems that no epistemic subject can know that $p$ unless s/he accepts $p$, without thereby risking error with respect to $p$. But the only way that any epistemic subject can avoid risking error with respect to a contingent proposition, is by not accepting it. Hence for any contingent proposition $p$, nobody knows that $p$. Moreover, if there are contingent propositions, some of those propositions are contingent truths. So if there are contingent propositions, there are truths that no one knows. In which case no one knows everything, so no one is omniscient. If there is an open future, there isn't an omniscient God.

Where - if anywhere - does this argument break down?

William of Occam would say: at premiss (5). Whenever $p$ is a contingent truth, it is true that

God accepts that $p$, and it's (still) possible that it's not the case that $p$. and false that 
It's (still) possible that: God accepts that $p$, although it's not the case that $p .^{1}$

(5) is the principle which underwrites the inference from God accepts that $p$ and $p$ is contingent to God risks error with respect to $p$. So, by denying (5), Occam can insist that, in spite of the contingency of $p$, God accepts $p$ without thereby incurring the risk of error with respect to $p$.

But how could God commit Himself to a proposition that is still, as it were, at risk of falsity, without thereby exposing Himself to the risk of error (with respect to that proposition)? I have argued elsewhere ${ }^{2}$ that if (as Occam seems to suppose) we suppose that God and His judgments are in time, then (as Occam forthrightly admits) there is something deeply mysterious about the idea that God commits to propositions at risk of falsity, without thereby incurring the risk of error.If risk of error with respect to a proposition $p$ (on the part of the accepter of $p$ ) and liability to falsity (on the part of the accepted proposition $p$ ) are a package deal, then it will be true that

(A) If someone now accepts that $p$, and it's (still) possible that it's not the case that $p$, then it's possible that: that someone now accepts that $p$, even though it's not the case that $p$.

But it does not follow that:

(B) If someone will accept $p$, and it's (still) possible that it's not the case that $p$, then it's (still) possible that: someone will accept that $p$, even though it's not the case that $p$.

Suppose that although Elizabeth will in fact exist, and know that she exists, her (future) existence is not (as of now) inevitable. On those assumptions:

Elizabeth will accept that she existed, or exists, or will exist, and it's still possible that she never did and never will exist.

But (for Cartesian reasons) it is obviously false that:

It's (still) possible that: Elizabeth will accept that she exists, even though she never did and never will exist.

To say that risk of error (on the part of the accepter of a proposition) and liability to falsity (on the part of the proposition accepted) go hand

\footnotetext{
${ }^{1}$ For more on Occam's take on premiss (5), see my "Ockham on An Argument Against God's Knowledge of Future Contingents", in A. Cirino and J. Reischl, eds., A Pilgrimage Through the Franciscan Tradition (Canterbury: Franciscan International Study Centre, 2008).

${ }^{2}$ See "Ockham on An Argument Against God's Knowledge of Future Contingents".
} 
in hand is not to deny that it may be true of one and the same proposition $p$ both that it's liable to falsity at an earlier time, and that its accepter (at a later time) is not (then) at risk of error with respect to that proposition. The proposition, Elizabeth existed or exists or will exist is right now at risk of falsity. But at no time will Elizabeth risk error by accepting it, since her acceptance of it implies its truth.

Now assuming that God and His judgments are in time, (5) is true as long as it's true that

(5')If God now accepts that $p$, and it's still possible that it's not the case that $p$, then it's (still) possible that: God now accepts that $p$, even though it's not the case that $p$.

But according to Boethius, the eternal present or nunc stans ("permanent now") that God and His judgments inhabit is an "un-time". If it is, then (5) could be false, even if (5') is true, as long as it is not true that

$\left(5^{\star}\right)$ If God timelessly accepts that $p$, and it's still (i.e. now) possible that's it's not the case that $p$, then it's still (i.e. now) possible that: God timelessly accepts that $p$, even though it's not the case that $p$.

And why should $\left(5^{\star}\right)$ be true - even assuming that liability to falsity on the part of the proposition accepted and risk of error on the part of the accepter of the proposition go hand in hand? Why couldn't it be that that proposition is now at risk of falsity, but God is not at risk of error with respect to that proposition "unwhen" He accepts it (inasmuch as that proposition is not "unthen" at risk of falsity)?

The moral I want to draw is that, if we want to resist the argument set out above by (conceding the first four premises and) challenging premiss (5), we shall have a harder time motivating that challenge if we assume that God and His knowledge are temporal, than if we assume that they are extratemporal.

Of course, "temporalists" about God and His knowledge can challenge one of the premises before (5), enabling them to block the argument, despite conceding the truth of (5). In what follows, I shall consider the most promising way of implementing this strategy.

\section{OPENNESS, PRIVILEGE, AND TRUTH}

It appears that there are many different (complete) ways the future might still go. Occam and many other philosophers who accept that things are 
as they appear hold that of those many (complete) ways the future could still go, one is special, or "privileged". That is, they hold that among the many different (complete) ways the future might still go, there is (just) one of which it is true that that is the way things not only might still go, but will in fact go. (As I'll understand it) there is a privileged future is equivalent to there are many still genuinely possible (complete) futures, and one of them is actual. ${ }^{3}$

By inclusivism, I shall understand the view that:

Just as the real includes not just the individuals and events that there are here, but also the individuals and events there are in any other place, so too the real includes not just the individuals and events that there are now, but also the individuals and events that there are at any other (past or future) time. Just as there really are (exclusively) "otherplacely" individuals and events, there really are (exclusively) "othertimely" individuals and events - future ones, as well as past ones. Reality "extends into" the future as well as the past.

What is the relation between inclusivism and the doctrine of privilege? It should be clear that inclusivism does not imply the existence of a privileged future, inasmuch as inclusivism is perfectly compatible with (indeed, some philosophers think, implies!) the claim that there is only one genuinely possible future. For reasons to be made explicit later, though, one would expect those who countenance a plurality of still possible futures, and accept inclusivism, to believe in a privileged future, which includes just those (future-located) individuals and events that are actually included in the real.

On the other hand, the doctrine of privilege does not evidently imply inclusivism. Even though many celebrated exclusivists have denied privilege (among them, C. D. Broad and Arthur Prior), the following view is not manifestly incoherent:

\footnotetext{
${ }^{3}$ A terminological note: the future is often understood as, so to speak, the venue in which things might go different ways, and will go some way or other. On that understanding of "future", the idea that there are many (complete) possible futures - that is, many different (maximal) venues in which things could go different ways, and will go some way or other - is bizarre. In what follows, though, I shall conform to the usage of many philosophical logicians, in using the term "future" to mean "way things will go", and "possible future" to mean "way things might (still) go". Thus, as I understand it there is a privileged now-possible (complete) future means there is a privileged now-possible (complete) way things will go.
} 
(However things might stand with individuals or events located (exclusively) in the past), there are no individuals or events located (exclusively) in the future. The real does not include anything located (exclusively) in the future; nevertheless, it is true both that there are many different ways things could still go, and (just) one way they will in fact go.

Someone might try to elaborate and motivate this view as follows:

Suppose that a certain pair of (currently existing) human gametes $G$ and $G^{\prime}$ could (still) combine, and that if they did combine, a particular human being, whom we may call Sara, would come into existence. Suppose also that $G$ and $G$ ' will never in fact combine, and Sara will never in fact come into existence.

In that case, Sara's coming into existence is a now-possible state of affairs. But the fact that Sara could still come into existence does not imply that Sara is real (though non-actual), or that among the things there really are, are non-actual individuals. It is true that Sara could come to be, because there is a state of affairs, Sara's coming to be, which has the property of being still possible. That there is such a state of affairs, and that said state of affairs has the property of being (still) possible, do not jointly imply that there really is such an individual as Sara, or that there really are any inactualia (things that there actually aren't). If the state of affairs, Sara's coming to be were currently actualized, that would imply that Sara is among the things there really are. But a state of affairs can be real and be (still) possible, without being currently actualized. Now suppose that the gametes $G$ and $G$ ' will in fact combine, and that Sara will in fact come to be. That implies that Sara is among the things that there really are or will really be, but it does not imply that Sara is among the things that there really are. More generally, it does not imply that any individuals located (exclusively) in the future are among the things there really are; it only implies that there really is (now) a state of affairs, Sara's coming to be, which state of affairs has the property of futurity (of going-tobe-actualized-ness). Even assuming there aren't really any individuals located (exclusively) in the future, we may still maintain that although both Sara will come to be and Sara will never come to be are (still) possible states of affairs, one of them is privileged with respect to the other, inasmuch as one of them not only could still come about, but will in fact come about. Sara's coming to be and Sara's never coming to 
be are "partial" ways the future might go. There are also "total" ways that the future might go. (A way the future might go is total just in case, if we knew that the future would go that way, we would know not just something, but everything about what will happen). Total ways that the future might go are (complete) possible futures. So we may hold that of all the complete possible futures there are, (just) one is privileged, in that it is the total way the future might go that it will in fact go - without supposing that any individuals (or any events) located exclusively in the future appear in the inventory of realia. So we can accept the doctrine of privilege, and reject inclusivism.

(My claim here is that the sort of "exclusivist privilegism" sketched here is a live option, and not that it is ultimately defensible. Perhaps the idea that an (unactualized) state of affairs can be real, even though the individual it "involves" is not, is ultimately unintelligible, however tempting that idea may be when we think about certain modal truths. Even if that is so, I think (a different sort of) exclusivist privilegism might still be true - one on which there are no exclusively othertimely individuals or events, because all individuals and events are necessary and thus current (even if they have "non-abstract" properties temporarily or contingently). ${ }^{4}$ For reasons of brevity, I won't explore this sort of "Williamsonian" exclusivist privilegism further.)

The alternative to the doctrine of privilege is egalitarianism. Egalitarians think that no (complete) possible future is privileged with respect to the others. All the (complete) possible futures there are, are "equiactual" (or "equiunactual") as well as "equipossible" - either because (as Jonathan Edwards supposed) the actual future is the only possible one, or because there are many possible futures, none of which are actual. Egalitarians typically say they cannot make sense of the supposition that one (complete) possible future is, as it were, "already actual", assuming that alternative possible futures are still genuinely possible. As they see it, if there are many still possible futures, all of them are still possible (insofar as they could each still happen), and none of them is actual yet (insofar as none of them has actually happened yet).

Whether or not egalitarianism is true, it is surely a live option. One could devote an article - or indeed a book - to the defence of this claim, but I shall make do with the following: exclusivism is a live option. As philosophers from Augustine right through to Prior have averred, there

\footnotetext{
${ }^{4}$ See Timothy Williamson, “Bare Possibilia”, Erkenntnis, 48 (1988).
} 
is nothing obvious about the idea that the real includes individuals that do not exist and never have existed, or events that never took place, and are not taking place. Since exclusivism is not obviously incompatible with the doctrine of privilege, the defensibility of exclusivism does not obviously imply the defensibility of egalitarianism. Nevertheless, there is a very natural line of thought that leads from inclusivism to the rejection of egalitarianism, and no obviously natural line of thought that leads from exclusivism to the rejection of egalitarianism. Egalitarians hold that reality is neutral with respect to the future existence or otherwise of Sara. Well, maybe not completely neutral: reality might make either her existence or her non-existence more likely than the alternative. But egalitarians think that reality does not settle the question of the future existence or otherwise of Sara. How could they make this claim, if inclusivism were true? After all, if inclusivism is true, then perhaps reality includes a (future-located) Sara, thus settling the question of whether Sara will come into existence. If on the other hand exclusivism is true, then Sara is no more real than the daughter my wife and I would have had if the sperm cell from which our first daughter came had fertilized the egg cell from which our second daughter came. The daughter we would have had in the circumstances just described is permanently and inevitably a mere possibile, and the same cannot be said for Sara. But the fact remains that (for the standard exclusivist) Sara is possible, but unreal. And (for the exclusivist) the same goes for all individuals or events located (exclusively) in the future. So (by the exclusivist's lights) inasmuch as anything we might call "the future" is real, it is real only as actualisable-but-not-yet-actualized (sufficiently comprehensive) state of affairs. And - unless openness is an illusion - there are many actualisable-but-not-yet-actualized (sufficiently comprehensive) states of affairs. Why suppose that any one of those actualisable-but-notyet-actualized and sufficiently comprehensive states of affairs deserves the name of the (complete) actual future? If we think of the future as analogous to the totality of things going on in a given "elsewhere" now - say, in the southern hemisphere - then it will seem obvious that there is a privileged future. For it seems obvious that there is some (maximal) bunch of the things going on in the southern hemisphere now, and of all the possible maximal bunches of things that might have been going on in the southern hemisphere now, one of them is privileged with respect to the others, in being the one and only (maximal) bunch of things that not only might have been going on there now, but is in fact going on 
there now. But of course, the analogy drawn between othertimely and otherplacely events is part of an inclusivist way of thinking about the future: for the exclusivist, although there really are lots of things going on in the southern hemisphere now, there aren't really any things happening in the future. If the real does not include any of the diverse (exclusively future-located) individuals or events it might yet come to contain, why suppose that reality must include something which makes it true that, although the real might come to contain either these individuals and events or those individuals and events, it will in fact come to contain these ones, rather than those ones?

Suppose that egalitarianism were true. What implications would that have for the relation between (historical) contingency and truth? Let us say that a proposition is (historically) contingent at a time just in case there is a (complete) then possible history in or according to which that proposition is true (then), and there is a (complete) then possible history in or according to which that proposition is not true (then). A proposition can be contingent (at a time) without being true (at that time). After all, if in ten minutes time, you'll be having a cup of tea is contingent (now), the same goes for in ten minutes time, you won't be having a cup of tea. And in ten minutes time, you'll be having a cup of tea and in ten minutes time, you won't be having a cup of tea can't both be true (now (or ever)). So a proposition can be contingent (now), without being true (now). On the other hand, a proposition cannot be contingently true (now), without being contingent (now), any more than a proposition can be contingently true (now), without being true (now). So, under what conditions will a proposition be not just contingent (at a time) but also contingently true (at that time)? The obvious answer is: if and only if it is true (then) in the actual then possible history, though not true (then) in all then possible histories. In other words, a proposition is contingently true at a time just in

${ }^{5}$ Here someone might object: there is no (complete) way things will go is obviously false. So there is some (complete) way things will go is obviously true. So there is an actual (complete) future, and an actual (complete) history. Given the (very plausible) assumption that there are many (still) possible histories, we may conclude that there is a privileged history. The egalitarian will reply that while things will go some (complete) way or other, there is no particular (complete) way things will go. (Compare: antimolinists say that if you faced a certain moral dilemma, you would make some choice or other, but deny that there is a particular choice you would make, if you faced that dilemma. And a horse-promiser might say that although she promised you some horse or other, there's no particular horse she promised you.) 
case it is true then in the privileged then possible history, but isn't true then in all then possible histories. Contingent truth is truth in the privileged history + untruth in some unprivileged (but still possible) history.

But egalitarians do not believe there is any such thing as the privileged history. So egalitarians don't believe there are any such things as (historically) contingent truths. Unless they are Edwardians, they will believe in (historically) contingent propositions, all of which are untruths.

\section{EGALITARIANISM AND THE ARGUMENT FOR THE INCOMPATIBILITY OF OPENNESS AND OMNISCIENCE}

It follows that egalitarians can take issue with our main argument for the incompatibility of openness with omniscience long before we get to premiss (5): they can say that (2) does not follow from (1), and is false, even if (1) is true. So egalitarians needn't challenge (5). Indeed, one would suspect that egalitarians would not want to challenge it (at least as long as (5) is understood in a straightforwardly "temporalist" way). As egalitarians see it, since no truths are (historically) contingent, all truths are (historically) necessary. So, for an egalitarian, $p$ and it is possible that $q$ will be true only if $p$ is (historically) necessary (as well as true), and $q$ is (historically) possible. If however, it is (historically) necessary that $p$, and it is (historically) possible that $q$, then it is (historically) possible that: both $p$ and $q$. (Think about it this way: if $p$ is true now in every now possible history, and $q$ is true now in some now possible history, then $p \& q$ is true now in some now possible history (in all and only those now possible histories in which $q$ is true.) Since egalitarians hold that

$p$ and it's (historically) possible that $q$

implies

it's (historically) possible that: both $p$ and $q$,

they hold that

God (now) accepts that $p$ and it's (still) possible that it's not the case that $p$

implies

it's (still) possible that: God (now) accepts that p, even though it's not the case that $\mathrm{p}$.

One would accordingly expect egalitarians to be happy with (5) (again, given a straightforwardly "temporalist" reading thereof). This means that, at least in one respect, egalitarians are better placed to block 
the argument at issue than "temporalists" ("anti-boethians") about God who would block the argument by sticking at (5) (e.g., Alvin Plantinga). As we have seen, and as Occam concedes, it is difficult to understand how (5) could be false (on a straightforwardly temporalist reading), which makes (5) (straightforwardly read) hard to challenge. If the egalitarian doesn't need to make that challenge, so much the better for her.

So we now have on the table two strategies for blocking our main argument for the incompatibility of openness with omniscience. The first turns on challenging (5), and - if I am right - is difficult to motivate unless God is outside time. The second turns on the rejection of (2). It certainly does not depend on the supposition that God is extatemporal. This again might be thought to tell in its favour. There are various worries we might have about divine extratemporality. If we are attracted by presentism, we may be inclined to think that existing implies existing in the (temporal) present. If we are attracted by inclusivism, we may be inclined to think that existing implies existing at some (past, present, or future) time. Even if we are happy to countenance extratemporalia - say, because, like Quine or Lewis we think of numbers and pure sets as extratemporal - we may well worry about the idea of extratemporal beings that stand in causal relations to temporal ones (as an extratemporal God would have to). Even if we have no such worries, we may worry (as Norman Kretzmann once did) about whether an extratemporal being would really be in a position to know everything there is to know about a temporal world. ${ }^{6}$

So it might be thought that the egalitarian approach to blocking our argument is, at least in certain respects, preferable to approaches which turn on challenging (5), whether those approaches involve a Boethian or an anti-boethian conception of God's knowledge. In what follows, I shall try to ascertain how workable the egalitarian strategy for blocking our main argument is. My approach will be to consider in turn the three best-known versions of egalitarianism, and investigate to what extent they put us in a good position to block the main argument.

\section{PEIRCEAN EGALITARIANISM}

If no proposition is both contingent and true, what should we say about the truth-value of a proposition at a time when it is contingent? (I put the

${ }^{6}$ Cf. Norman Kretzmann, "Omniscience and Immutability", in B. Brody, Readings in the Philosophy of Religion (Englewood Cliffs, NJ: Prentice Hall, 1974). 
point this way because a proposition may be (historically) contingent at one time, but not at another: on the assumption that your existence was not always inevitable, you existed or you exist or you will exist was once contingent, but is now (historically) necessary). Peircean egalitarians hold that (necessarily) when propositions are contingent, they are false. Assuming that $p$ implies $q$ just in case $p$ could not be true, unless $q$ were, this amounts to saying that just as it is inevitable that $p$ implies $p, p$ implies it is inevitable that $p$. So for, Peircean egalitarians, $p$ means that - or at any rate "comes to" (necessarily has the same truth value as, is logically equivalent to) it is inevitable that $p .^{\text {? }}$

From what Willard van Orman Quine would call "the logical point of view", Peircean egalitarianism has many attractions. Classical logic offers us a tidy package, which includes the law of non-contradiction (according to which not: both $p$ and it's not the case $p$ is true, for all $p$ ), the law of excluded middle (according to which $p$ or it's not the case that $p$ is true, for all $p$ ) and bivalence (according which $p$ is true or false, for all $p$ ). Peircean egalitarians can accept the whole package, ending up with a simple, straightforward, and for the most part unsurprising logic. Perhaps the most obvious surprise is that pairs such as in ten years you'll be married, in ten years you won't be married $\}$ turn out to be contraries but not contradictories. (For the Peircean, they are contraries, inasmuch at least one must be false, but they are not contradictories, inasmuch as they could both be false (will both be false, if it's contingent whether in ten years time, you'll be married).

Despite its logical tidiness, Peircean egalitarianism is severely problematic. Perhaps the most central problem is that $p$ and it is historically necessary (inevitable, settled) that $p$ do not in fact seem to be equivalent: inevitably $p$ seems different from (and stronger than) $p$.

There are various ways in which we can bring this point out. Here's one: if $p$ and $q$ are logically equivalent, then no one who is sufficiently informed about logic, and sufficiently rational, can believe that $p$ without believing that $q$. If for example, that's a rabbit only if it is an animal is logically equivalent to if that's a rabbit, it's an animal, then no one who knows enough logic (in this case, knows enough about the logic of conditionals), and is sufficiently rational, can believe the former, but not the latter. It seems as though this principle also holds for such

${ }^{7}$ For a discussion of Peircean egalitarianism, see A. Prior, "Time and Determinism", in his Past, Present, and Future (Oxford: Clarendon Press, 1966). 
propositional attitudes as hoping and fearing. If that rabbit will feel much better tomorrow is logically equivalent to the (more cumbersome) it's not the case that it's not the case that that rabbit will feel much better tomorrow, then no one who knows enough logic (in this case, knows enough about negation), and is sufficiently rational, can hope that that rabbit will feel much better tomorrow, without hoping that it's not the case that it's not the case that that rabbit will feel better tomorrow. To take another case, if it's raining is logically equivalent to it's actually raining, or it's raining now, then no one who is sufficiently informed about logic, and sufficiently rational, can fear that it's raining, but not fear that it's actually raining, or that it's raining now.

Now for Peircean egalitarians, $p$ and it is (historically) necessary that $p$ (it is inevitable that $p$, it is settled that $p$ ) are logically equivalent. So it seems that Peirceans should accept that no one who is sufficiently informed about logic, and sufficiently rational, can fear that $p$, without fearing that it is inevitable that $p$. But this is very hard to believe. Surely, however much I knew about logic, I could entirely rationally fear that something will happen (because I think it could still happen, and I'd very much rather it didn't), even though I do not fear that it inevitably will happen (because I'm sure that it's not inevitably going to happen). I suspect that Peircean egalitarians themselves, whatever their official views on truth and inevitability, in fact sometimes find themselves in the position of hoping or fearing that $p$, without hoping or fearing that it is inevitable that $p$. (For example, if they think that there are free choices, and think that it cannot be inevitable that someone will freely choose this, then they will sometimes find themselves in the position of hoping or fearing that someone will freely choose this, without hoping or fearing that it is inevitable that someone will freely choose this). If my suspicions are well-founded, Peircean egalitarians themselves have propositional attitudes that, by their lights, they could not rationally have, if they were sufficiently well-informed logically. ${ }^{8}$

\footnotetext{
${ }^{8}$ John Burgess (in "The Unreal Future", Theoria 4 (1978)), and Prior (in "Time and Determinism") consider (but do not endorse) the worry that Perircean egalitarians cannot give a satisfactory account of propositional attitudes such as expecting, hoping, or fearing. In the latter piece, Prior discusses (but does not endorse) the idea that Peircean (egalitarian) tense logic is a mere fragment of Occamist (= privilegist)) tense logic, which contains a "strong future" (it will inevitably be that), but no "plain" or "weak" future" (it will be that). The points just raised concerning fearing and hoping suggest that there is indeed a "weak" future that Peircean egalitarians leave out of their tense logic.
} 
A second argument for the non-equivalence of $p$ and it is (historically) necessary that $p$ involves explicit reference to truth and falsity. Imagine the following bit of dialogue:

A: Just tell me what's going on, without beating around the bush.

Next year Jones will still be here - true or false?

B: False.

A: Thank you. Last question: next year Jones will be gone - true or false?

B: ???

B would no doubt be puzzled about why A needed to ask the second question, given B's answer to the first one: if next year Jones will still be here is false, then next year Jones will be gone is true. For someone who takes $p$ and it is inevitable that $p$ to be equivalent, though, A's second question is a perfectly sensible one. Assume it's open whether Jones will be here next year. Then both it is inevitable that next year Jones will be here and it is inevitable that next year Jones will be gone are false. So, on the assumption that $p$ and it is inevitable that $p$ are (logically) equivalent, both next year Jones will be here and next year Jones will be gone are false. On the other hand, assume that it's inevitable that next year Jones will be gone. Then (whatever we assume about the equivalence or otherwise of $p$ and it is inevitable that $p$ ), next year Jones will be here will be false, and next year Jones will be gone will be true. So, for Peircean egalitarians, B's second question is not otiose - which seems wrong.

Last argument for the non-equivalence of $p$ and it is (historically) necessary that $p$ : something might be permitted in one system of laws, but not in another. For example, polygamy might be permitted in a system of laws $L$, and not in a system of laws $L$. Let us call something that is permitted in a particular system of laws $L L$-legal, and something that is proscribed in a particular system of laws $L$ L-illegal. If something is $L$-legal, or $L$-illegal, it is inevitably so. (The laws on polygamy might change someday, in such a way as to make polygamy legal; but, where $L$ is the system of laws currently in force in England, it would still be true that polygamy is $L$-illegal, even after polygamy had been legalized). Imagine a society with a legal system $L^{*}$ that proscribes what we might call "serial polygamy" - that is, a legal system which proscribes marrying more than one person over the course of a life (and not just marrying more than one person at a time). In this society it is true that:

It is inevitable that the number of persons you will ( $L^{*}$-legally) marry is less than 2 . 
But (assuming you haven't yet married), it can perfectly well be false both that:

It is inevitable that the number of persons you will ( $L^{*}$-legally) marry $=0$. and that

It is inevitable that the number of persons you will ( $L^{*}$-legally) marry $=1$.

For Peircean egalitarians, since $p$ implies as well as being implied by it is necessary that $p$, it is necessary that is a "redundant" operator, like indeed. We can "subtract" it without making any difference to the truthvalue of a statement. So Peirceans will have to say that, in the case under discussion it could be true that:

(i) The number of persons you will ( $L^{*}$-legally) marry is less than 2 . and false both that

(ii) The number of persons you will ( $L^{\star}$-legally) marry $=1$. and that

(iii) The number of persons you will ( $L^{*}$-legally) marry $=0$. But how can this be? If (i) is true, and (ii) and (iii) are false, then the following conditional is false:

(iv) If you'll ( $L^{*}$-legally) marry fewer than two persons, either you'll ( $L^{*}$-legally) marry one person, or you won't ( $L^{*}$-legally) marry. - and (iv) is surely true! What we want to say, intuitively, is that (iv) is true, although it would become false if in (iv) we uniformly replaced “you'll ( $L^{*}$-legally marry)" by “you'll inevitably ( $L^{\star}$-legally) marry"; and Peircean egalitarianism leaves us no room to say that.

Summing up: if egalitarians say that $p$ is (not just untrue, but) false when it's contingent whether $p$, inasmuch as $p$ and it is (historically) necessary that $p$ are equivalent, they end up with a tidy logic, but not a few headaches. On the other hand, without a privileged future, it's hard to see how we can accept bivalence, without accepting the equivalence of $p$ and it is (historically) necessary that $p$. Absent a privileged future, whenever it is contingent whether $p$, $p$ will be untrue. Assuming bivalence, if $p$ is untrue, $p$ is false. So if it's contingent whether $p$, it is false that $p$. Equally, if it's impossible that $p$, it is false that $p$. And of course, if it is necessary that $p$, it is true that $p$. So $p$ is true if it's necessary that $p$, and false otherwise (since whatever isn't necessary, is either contingent or impossible) - in which case $p$ and it's necessary that $p$ are equivalent. Moral: egalitarians have a motivation for considering "non-classical" accounts of the relation between truth and inevitability - that is, accounts that give us bivalence (whether or not they also give up the classical principles of non-contradiction and excluded middle). 


\section{NON-CLASSICAL EGALITARIANISM}

If the future is open, then there are different (still) possible (complete) histories "branching out" from the future, in which different things happen. So an egalitarian who shares the worries I have tried to raise about the equivalence of $p$ and it is (historically) necessary that $p$ might naturally make the following suggestion:

A proposition such as you'll eat cake tonight is true (now) if it is true (now) in every (still) possible history. It is false (now) if it is false (now) in every (still) possible history. And it is indeterminate (neither true nor false) (now) if it is true (now) in some but not all (still) possible histories.

If the egalitarian makes this (arguably, though not uncontroversially) Aristotelian move, she can say that $p$ and it is (historically) necessary that $p$ are not equivalent, inasmuch as $p$ is indeterminate, and it is (historically) necessary that $p$ is false, when $p$ is true in only some still possible histories. It is necessary that $p$ and $p$ may still imply each other (if we say that $p$ implies $q$ just in case $p$ cannot be true without $q$ being true), but $p$ and it is necessary that $p$ won't "come to the same thing", in that they can have different truth values. So the suggestion just made allows the egalitarian to reject what (she takes to be) the myth of privilege, without having to accept equivalence and its discontents.

In fact, independently of the worries raised about equivalence, the suggestion under consideration might well attract egalitarians, because it is pleasingly symmetrical. For any egalitarian, things will go this way is untrue as long as things might still go a different way. So why not say, symmetrically, that things will go this way is unfalse, if things might still go this way? Unless we say that, we'll make it "easier" for things will go this way to be false, than for it be true. Now if we are already committed to the equivalence of things will go this way and things will necessarily go this way, there will be nothing surprising about the idea that it's "easier" for things will go this way to be false, than it is for it to be true: after all, it's "easier" for things will necessarily go this way to be false than it is for it to be true (in order for things will necessarily go this way to be true, it is required that things go this way in every still possible history; in order for things will necessarily go this way to be false, it is only required that things fail to go that way in one still possible history). But, absent an antecedent commitment to the equivalence of $p$ and it is necessary that $p$, 
it seems odd to build a "bias towards falsity" into our account of truths about the future.

So far, so good. But suppose an egalitarian says that you'll have cake tonight is true (now), false (now), or indeterminate (now) depending on whether it's true (now), in all, or no, or only some (still) possible histories. What should she say about "compound" statements built up from (one or more) simpler statements and sentential operators, such as it's not the case that you'll have cake tonight, you'll have cake tonight or you'll have coffee tonight, it's not the case that both: you'll have cake tonight and you'll have cake tonight, and the like? Classical logic provides an account of how the truth values of such compound statements are determined (exclusively) by the truth values of their simpler components (in a way that can be represented by truth tables), but the equivalence-denying egalitarian cannot help herself to (the entirety of) the classical logician's account of compound statements, since that implies bivalence, which the equivalence-denying egalitarian rejects. For the equivalence-denying egalitarian, what the classical logician says about negation (to wit: it's not the case that $p$ is true if $p$ is false, and false if $p$ is true) is part, but only part of the truth about negation, since it doesn't tell us what to say about the truth value of it's not the case that $p$ if $p$ is indeterminate.

At this point, equivalence-denying egalitarians come to a fork in the road. Some have followed Lukasiewicz in holding onto the classical logician's idea that we can give a "truth-tabular" (that is, a truth-functional) account of negation, disjunction, etc., and extending the classical account to cover cases in which one or more of the components of the compound statements are indeterminate. On this approach, we say something like:

It is not the case that $p$ is true (now) if $p$ is false (now), false (now) if $p$ is true (now), and indeterminate (now) if $p$ is indeterminate (now).

A conjunction of the form $p$ and $q$ is true (now) if both $p$ and $\mathrm{q}$ are true (now), false (now) if either $p$ is false (now) or $q$ is false (now), and indeterminate (now) at least one of $\{p, q\}$ is indeterminate (now), and neither is false (now).

A disjunction of the form $p$ or $q$ is true (now) if at least one of $\{p, q\}$ is true (now), false (now) if both $p$ and $q$ are false (now), and indeterminate (now) if at least one of $\{p, q\}$ is indeterminate (now), and neither is true (now). ${ }^{9}$

\footnotetext{
${ }^{9}$ For further discussion, see Prior's "Time and Determinism".
} 
On this approach, assuming you'll have cake tonight and you'll have coffee tonight are both open and thus indeterminate (now), it's not the case that you'll have cake tonight, it's not the case that you'll have coffee tonight, you'll have cake tonight or you'll have coffee tonight, and you'll have cake tonight and you'll have coffee tonight are all (indeterminate) now.

Arthur Prior, Richmond Thomason and others have argued that the approach just sketched is unsatisfactory, on the grounds that it makes disjunctions such as you'll have coffee tonight or it's not the case that you'll have coffee tonight untrue (now) (because indeterminate (now)), and conjunctions such as you'll have coffee tonight and it's not the case that you'll have coffee tonight unfalse (now) (because indeterminate (now)). As Prior, Thomason, et al. see it, you'll have coffee tonight and it's not the case that you'll have coffee tonight is a contradiction, and contradictions are always false (as well as never true). And if we accept the (eternal) falsity of you'll have coffee tonight and it's not the case that you'll have coffee tonight, and say the usual (and plausible) thing about the logical links between conjunctions and disjunctions, we'll have to say that you'll have coffee tonight or it's not the case that you'll have coffee tonight is always true (and not just never false). (Suppose $p$ and it's not the case that $p$ is false (now). Since $p$ and $q$ is false (now) just in case it's not the case that $p$ or it's not the case that $q$ is true (now), we can move from the (current) falsity of $p$ and it's not the case that $p$ to the (current) truth of it's not the case that $p$ or it's not the case that it's not the case that $p$. Given that it's not the case that it's not the case that $p$ is equivalent to $p$, we can move from the (current) truth of it's not the case that $p$ or it's not the case that it's not the case that $p$, to the (current) truth of it's not the case $p$ or $p$, and thus to the current truth of $p$ or it's not the case that $p$. So if $p$ and it's not the case that $p$ is forever false, then $p$ or it's not the case that $p$ is forever true).

As Prior et al. see it, the moral of the story is not that the Lukasiewiczian approach gives the wrong (three-valued) truth-tables for conjunctions and disjunctions. It is instead that equivalence-denying egalitarians shouldn't be in the business of providing truth-tables for conjunctions and disjunctions. A truth-tabular account of conjunction and disjunction is feasible only if the truth-value of a conjunction or disjunction depends only on the truth-values of its conjuncts or disjuncts. But, Prior and co. hold, equivalence-denying egalitarians should deny that the truthvalue of a conjunction or disjunction depends only on the truth-value of its conjuncts or disjuncts. For they should say that you'll have cake tonight and it's not the case that you'll have cake tonight is false (now), 
and that (the needlessly prolix) you'll have cake tonight and you'll have cake tonight is indeterminate (now), as long as you'll have cake tonight is indeterminate (now) Similarly, they should say that you'll have cake tonight or it's not the case that you'll have cake tonight is true (now), and (the needlessly prolix) you'll have cake tonight or you'll have cake tonight is indeterminate (now), assuming you'll have cake tonight is indeterminate (now). As Prior puts it (in "Time and Determinism"), on the assumption of equivalence-excluding egalitarianism, the truth-functional approach seems "simply out of place". A more radical departure from the classical account of conjunction and disjunction is needed.

What might such a departure look like? Richmond Thomason and others have made the following suggestion:

Start with the notion of truth at a time in a possible history. Assume that bivalence holds for truth at a time on a possible history: for example, if $t$ is a time, and $h$ is a possible history "passing through" $t$, it will be either true at $t$ on $h$ that you'll have cake, or it will be false at $t$ on $h$ that you'll have cake (It will be true at $t$ on $h$ that you'll have cake tonight if and only if at some $t$ ' belonging to $h$ and later than $t$ you have cake, and it will be false at $t$ on $h$ that you'll have cake tonight if and only if at no time $t^{\prime}$ belonging to $h$ and later than $t$ do you have cake.) Irrespective of whether a statement is simple or compound, we can distinguish three cases: (a) the statement will be true (at a time) on every then-possible history, (b) the statement will be true (at that time) on no then-possible history, and (c) the statement will be true (at that time) on some then-possible histories, and false (at that time) on some then-possible histories. If (a) holds, we say that the statement is true (then) (true (then) simpliciter, not just true (then) on this or that history). If (b) holds, we say that the statement is false (then) simpliciter. If (c) holds, we say that the statement is indeterminate (then) simpliciter. ${ }^{10}$

On this approach, the truth-value of conjunctions and disjunctions turns out not to depend exclusively on the truth values of their components, statements of the form $p$ and it's not the case that $p$ are always false, and statements of the form $p$ or it's not the case that $p$ are always true. A conjunction of the form $p$ and it's not the case that $p$ will be false at any given time $t$, because there will be no possible history passing through $t$ on which both conjuncts of that conjunction are true. A disjunction

${ }^{10}$ Cf. Richmond Thomason, "Indeterminist Time and Truth-value Gaps", Theoria 36 (1970). 
of the form $p$ or it's not the case that $p$ will be true at any given time $t$, because on every history passing through $h$, one or the other disjunct of that disjunction - and thus the entire disjunction - will be true. Truthfunctionality will fail, because you'll have cake or it's not the case that you won't have cake will be true (now), but you'll have cake or you'll have cake will be (indeterminate) now (assuming it's open whether you'll eat cake).

Not a few philosophical logicians have supposed that what we might call "Thomasonian" or "supervaluationalist" egalitarianism represents a real advance on the Lukasiewiczian kind. I'm not so sure. I agree that there is something at least initially compelling about the idea that contradictions are in every case false (as well as untrue), and the idea that every instance of the law of excluded middle is true (as well as unfalse). I'm not sure, though, that an equivalence-denying egalitarian (as opposed to a Peircean egalitarian, or a privilegist) is well placed to insist on the truth of those ideas. For I find the following claims at least initially compelling:

Reasoning that takes us from a pair of conjuncts to their conjunction is completely impeccable deductive reasoning.

If we start from premises none of which is false, and do nothing but reason deductively completely impeccably, we will never arrive at a false conclusion.

But it seems that these claims can't both be true, if Thomasonian egalitarianism is true.

Why? Well, suppose that $p$ is true in some but not all now-possible histories, and likewise $q$. Suppose also that the conjunction $p$ and $q$ is true in no now-possible history (either because $p$ and $q$ are logically inconsistent, or because, although $p$ and $q$ are logically consistent, there is some inevitably false $r$ that $p$ and $q$ jointly entail).

Suppose finally that someone forthrightly believes that $p$, and forthrightly believes that $q$ (because she takes herself to have very good evidence for both $p$ and $q$, and (a) she is unaware that $p$ and $q$ are logically inconsistent (the inconsistency is quite subtle, and escapes her notice), or (b) she is unaware that there is an inevitably false $r$ that $p$ and $q$ jointly imply). Now imagine this person reasoning as follows:

$\mathrm{p}$

$q$

Therefore: $p$ and $q$ 
I want to say that this person's reasoning is entirely irreproachable. But, given our assumptions about $p$ and $q$, and assuming Thomasonian egalitarianism, the reasoning moves from premisses none of which is false, to a false conclusion. I find this at least initially baffling. A person starts out clear of the briar patch of falsity. She reasons deductively in an utterly impeccable way, and as a result ends up in the thick of that briar patch. How can this be? Isn't impeccable (deductive) reasoning unfalsity-preserving, as well as truth-preserving?

Notice that if there is a difficulty for Thomasonian egalitarians here, it is not one they can address simply by insisting on the plausibility of what we might call strong non-contradiction and strong excluded middle. (Strong non-contradiction says that conjunctions of the form $p$ and not- $p$ are always false, as well as untrue; strong excluded middle says disjunctions of the form $p$ or not- $p$ are always true, as well as unfalse). It's not as though we have to choose between the principles about reasoning I find intuitive, and strong non-contradiction + strong excluded middle. We can have both, as long as we are either Peircean egalitarianists or privilegists (aka Occamists).

So I am inclined to think that both Lukasiewicizian and Thomasonian egalitarians have to deny some initially appealing principles. It is true, though, that a Thomasonian can offer the following tu quoque argument against a Lukasiewiczian:

Suppose $\mathrm{p}$ is indeterminate and $\mathrm{q}$ is false. Then for Lukasiewiczians, both $p$ or $q$, and it's not the case that $p$ will be indeterminate. But someone who reasons as follows $-p$ or $q$, it's not the case that $p$, therefore $q$ - is reasoning impeccably. So Lukasiewcizians, just like us Thomasonians, will have to say that impeccable reasoning need not preserve unfalsity. And unlike us Thomasonians, Lukasiewiczians will have to abandon the very plausible principle that $p$ or not $p$ is always true, and $p$ and not $p$ is always false.

Fair enough. There is an another respect in which Lukasiewiczian seems marginally problematic with respect to the Thomasonian kind. Both Thomasonian and Lukasiewiczian egalitarians will presumably have to admit there are cases in which a disjunction is true now in every still possible history, even though the same cannot be said for any of its disjuncts. (Assume you're in a society whose laws proscribe "serial polygamy", and have been single all your life. Then you'll (legally) marry zero persons or you'll (legally) marry one person is true (now) in every still 
possible history, but the same cannot be said for either disjunct of that disjunction). Thomasonian egalitarians can say that in such cases, the whole disjunction is both true (now) and inevitable (now), and both disjuncts are untrue and evitable (now). Lukasiewiczian egalitarians have to say that the whole disjunction is untrue (now) (since it is a disjunction with two (currently) untrue disjuncts). So they have two options. They can say:

The disjunction, you'll (legally) marry zero persons or you'll (legally) marry one person is true (now) in every still possible history, but it is not inevitable (now).

Or they can say:

The disjunction, you'll (legally) marry zero persons or you'll (legally) marry one person is inevitable (now), but it is not true (now).

Both options look pretty desperate: anything that would still be true, whichever now-possible future turned out to be actual, is inevitably true, and thus true.

\section{A WORRY FOR (ALL) EGALITARIANS}

Consider the following (three-way) conversation:

$\left(\mathrm{CV}_{1}\right) \quad A$ : It's inevitable that she'll marry him.

$B$ : That's not true.

$C$ : (to $B)$ : But didn't you say she could (still) marry him?

$B($ to $C)$ : I did say that, and I still think it's true. But what $A$ said is that she'll inevitably marry him, and that's not true.

Here, although C's question to $B$ is odd, there is nothing odd about $B$ 's part in the conversation. Now consider the following variant of $\left(\mathrm{CV}_{1}\right)$ : $\left(\mathrm{CV}_{2}\right) \quad$ A: She'll marry him.

$B$ : That's not true.

$C$ (to B): But didn't you say she could (still) marry him?

$B$ (to $C$ ): I did say that, and I still think it's true. But what $A$ said is that she'll marry him, and that's not true.

In $\left(\mathrm{CV}_{2}\right)$, I want to say, $C$ 's question is to $B$ is perfectly natural, and $B$ 's part in the conversation is odd. It's perfectly fine to acknowledge that she could still marry him, and also assert (flatly, without any hedging or qualification) that she will inevitably marry him is not true. But it's at least odd to acknowledge that she could still marry him, and also assert (flatly, without any hedging or qualification) that she will marry him is 
not true. Certainly, I would not do that, and I cannot recall ever having heard anyone else do it. If someone tells me that she'll marry him, and I believe that it's still possible but not yet inevitable that she'll marry him, then I might naturally say (without any hedging or qualification), "that's not necessarily true", or "that's not inevitable", but I wouldn't naturally say "not true!". (I would naturally say, "not true!", if we were living in a society whose laws proscribed serial polygamy, and I knew that she was already married to someone else (and I meant "legally marry" by "marry)"; that is, I would naturally say (without any hedging or qualification) "not true", if I thought it was inevitable that she wasn't going to (legally) marry him).

Believers in privilege have no difficulty explaining the (apparent) fact that $B$ 's contribution to $\left(\mathrm{CV}_{2}\right)$ is odd. They can say:

You are not supposed to assert something flatly (without hedging or qualification) unless you take yourself to know it. And in $\left(\mathrm{CV}_{2}\right)$, $B$ shouldn't take himself to know what he flatly asserts (that she won't marry him). For $B$ himself has admitted that there are now-possible histories in which she'll marry him, and should admit that for all he knows, the privileged now-possible history is such a history.

Egalitarians, on the other hand, seem ill-placed to explain (or explain away) the (apparent) oddity of $B$ 's contribution to $\left(\mathrm{CV}_{2}\right)$. They admit that, in the circumstances, there would be nothing untoward in B's asserting, without hedging or qualification, that it's open whether she'll marry him. And they think that it's open whether she'll marry him implies it's not true that she'll marry him. So why should there be anything untoward about $B$ 's asserting, without hedging or qualification, that it's not true that she'll marry him?

There are also cases of apparent conversational non-untowardness that privilegists have no trouble explaining, but egalitarians have trouble explaining (or explaining away). Consider

$\left(\mathrm{CV}_{3}\right)$ A: She'll marry him.

$B$ : I doubt that's true, though I grant things could go either way.

Here B's contribution to $\left(\mathrm{CV}_{3}\right)$ seems perfectly in order. This raises problems for egalitarians. If you think that $p$ is incompatible with $q$, you shouldn't say, "I doubt that $p$, though I grant that $q$ ": the adversative ("though") is inapposite. (Compare: "I doubt that's a golden retriever, though I grant that it's a guinea pig.") For example, if you think (as you should), that it is inevitable that $p$ is incompatible with $p$ could still go either way, you shouldn't say, "I doubt it's inevitable that $p$, though 
I grant $p$ could go either way". And if someone else says to you, "I doubt it's inevitable that $p$, though I grant $p$ could go either way", you should respond that that's not the right way to put things. Now egalitarians think that just as it is inevitable that $p$ is incompatible with $p$ could still go either way, it is true that $p$ is incompatible with $p$ could go either way. So they should never say, "I doubt that's true, though I grant things could go either way". And if someone else says that to them, they should respond, "that's not the right way to put things". Egalitarians must insist on the untowardness of $B$ 's contribution to $\left(\mathrm{CV}_{3}\right)$. Again, I find this more than slightly counterintuitive.

It may be worth underscoring that the worries raised here apply in equal measure not just to the three forms of egalitarianism discussed here, but to any possible form thereof. For the worries turn on the assumption that contingency implies untruth, and you can't be an egalitarian without accepting that assumption.

\section{VARIETIES OF EGALITARIANISM AND THE MAIN ARGUMENT}

Suppose that, despite the many and varied difficulties besetting the forms of egalitarianism discussed here, (some form of) egalitarianism is as defensible as privilegism. On that supposition, for reasons already discussed, it is at least arguable that the egalitarian is in a better position than the (premiss (5) challenging) privilegist to insist on the reality of an omniscient God and an open future, in the face of the main argument. (Again, privilegists who concede (2) and challenge (5) have two options: they can say that (mysteriously) God can (now) accept (now) falsityliable propositions without thereby incurring risk of error, or they can insist on God's extratemporality. Each of these options would seem more problematic than the denial of (2), on the assumption that some form of egalitarianism is as defensible as privilegism.)

Now we can raise the same question about the particular forms of egalitarianism discussed so far that we just raised (and (tentatively) answered) about egalitarianism in general. That is, we can ask: assuming that Peircean (Lukasiewiczian, Thomasonian) egalitarianism is as defensible as privilegism, is the Peircean (Lukasiewiczian, Thomasonian) egalitarian better placed than the (premises (5) challenging) privilegist to insist on the reality of an omniscient God and an open future, in the face of the main argument? 
As best I can tell, the Peircean egalitarian is indeed better placed to fend off the main argument than the premiss (5) challenging privilegist, on the assumption that Peircean egalitarianism is no more problematic than privilegism. And it might seem obvious that the same goes for Lukasiewiczian and Thomasonian egalitarians. But it isn't.

Assume it's open whether you'll have cake tonight. Then, for Lukasiewiczian egalitarians, it's indeterminate whether you'll have cake tonight. Now consider the following pair of conjunctions:

(A) You will have cake tonight, and it's not the case that God accepts you will.

and

(B) You won't have cake tonight, and God does accept that you will.

Lukasiewiczians will say that (A) is untrue, because its left conjunct is indeterminate. Its right conjunct might be (i) true, (ii) false, or (iii) indeterminate. If the right conjunct of (A) is true, then (A) is a conjunction with one indeterminate and one true conjunct, and is accordingly indeterminate. If the right hand conjunct of $(\mathrm{A})$ is false, then $(\mathrm{A})$ is a conjunction with one indeterminate and one false conjunct, and is accordingly false. If the right hand conjunct of $(A)$ is indeterminate, then $(\mathrm{A})$ is a conjunction both of whose conjuncts are indeterminate, and is accordingly indeterminate.

If the right conjunct of $(A)$ is true, then the right conjunct of (B) is false. And if the right conjunct of $(B)$ is false, then (B) is a conjunction with one indeterminate conjunct and one false conjunct, and is accordingly false.

If the right conjunct of $(\mathrm{A})$ is indeterminate, then the right conjunct of (B) is likewise indeterminate. And if the right conjunct of (B) is indeterminate, $(\mathrm{B})$ is a conjunction with two indeterminate conjuncts, and is accordingly indeterminate. If on the other hand, the right conjunct of (A) is false (so that (A) itself is false), then (B) is a conjunction with one indeterminate conjunct and one true conjunct, and is thus once again indeterminate.

Summing up: (A) is either indeterminate or false. If (A) is indeterminate, (B) will be false (if the right conjunct of (A) is true), or indeterminate (if the right conjunct of $(A)$ is either indeterminate or false). If (A) is false, (B) will be indeterminate (since it will have one indeterminate and one true conjunct). So, on Lukasiewiczian assumptions, there's no way for $(\mathrm{A})$ and $(\mathrm{B})$ to both be false. If we suppose 
that the right conjunct of (A) is (not just untrue but) false, we can make (A) itself come out false; but that will make (B) come out indeterminate (since (B) will be a conjunction with one indeterminate and one true conjunct). Symmetrically, if we suppose the right conjunct of (B) is (not just indeterminate but) false, we can make (B) itself come out false; but that will make $(\mathrm{A})$ indeterminate (since $(\mathrm{A})$ will be a conjunction with one indeterminate and one true conjunct).

Now (A) and (B) may be rephrased (respectively) as:

(A') You're going to have cake tonight, even though God doesn't accept you will.

and

(B') God accepts that you're going to have cake tonight, even though you won't.

So, for a Lukasiewiczian egalitarian, at least one of $\left\{\left(\mathrm{A}^{\prime}\right),\left(\mathrm{B}^{\prime}\right)\right\}$ is indeterminate, rather than false. Surely, though, if there is an omniscient God is true, then both (A') and (B') are false (and not just untrue). It doesn't seem to make sense to say:

There is an omniscient God; that's true. That said, someone who believed that either (a') you're going to have cake tonight, even though God doesn't realize you will, or (b') God thinks you're going to have cake tonight, even though God thinks you won't, wouldn't believe anything false. Either things will go a certain way, though God doesn't think they will or God thinks things will go a certain way, even though they won't is unfalse, but there truly is an omniscient God.

If it doesn't make sense, then - even on the assumption that Lukasiewiczian egalitarianism is as defensible as privilegism - it's of no use to anyone who wants to defend the reality of an open future and an omniscient God, in the teeth of our main argument.

Assume now that Thomasonian egalitarianism is as defensible as privilegism. On that assumption, is the Thomasonian in a better position than the (premiss (5) challenging privilegist) to hold on to an omniscient God and an open future, in the teeth of our main argument? Surprisingly, it seems not.

It seems that a Lukasiewiczian egalitarian (who thinks it's open whether you'll have cake tonight) could deny the (current) truth of

Either God accepts that you will have cake tonight, but it's still possible that you won't have cake tonight, or God does not accept that you will have cake tonight, but it's still possible that you won't have cake tonight. 
on the grounds that neither disjunct of the above disjunction is true (now), because neither God accepts that you'll have cake tonight nor God does not accept that you'll have cake tonight is true (now). But a Thomasonian egalitarian cannot make this move. Think of it this way: Where $p=$ God accepts that you'll have cake tonight, the Thomasonian holds that $p$ or not- $p$ is true (now), because it is true (now) on every now-possible history. Where $q=$ it's contingent whether you'll have cake tonight, the Thomasonian (who thinks it's open whether you'll have cake tonight) again holds that $q$ is true (now), because it is true (now) on every now-possible history. So, (for Thomasonians (who accept the openness of your having cake tonight)) $p$ or not- $p$ and $q$ are both true. By elementary logic, this implies $p$ and $q$ or not- $p$ and $q$. Translating back into English, (for Thomasonians (who accept the openness of your having cake tonight)) it's true that:

(a) (Either God accepts that you will have cake tonight, but it's (historically) contingent whether you will have cake tonight, or God does not accept that you'll have cake tonight, but it's (historically) contingent whether you will have cake tonight.

Since it's (historically) contingent whether you'll have cake tonight implies both it's (still) possible that you'll have cake tonight, and it's (still) possible that you won't have cake tonight, $(\alpha)$ implies

$(\beta)$ Either God accepts that you will have cake tonight, but it's (still) possible that you won't have cake tonight, or God does not accept that you will have cake tonight, but it's (still) possible that you will have cake tonight.

If God accepts that you'll have cake tonight, but it's still possible that you won't, or God does not accept that you will have cake tonight, but it's still possible that you will, could there be an omniscient God? No assuming that

$(\gamma)$ God accepts you'll have cake tonight, but it's (still) possible that you won't.

implies

( $\delta)$ It's (still) possible that: God accepts you'll have cake tonight, even though you won't have cake tonight.

and that 
(ع) God does not accept you'll have cake tonight, but it's (still) possible that you will have cake tonight.

implies

( $)$ It's (still) possible that: God does not accept that you'll have cake tonight, but you will have cake tonight.

If $(\gamma)$ implies $(\delta)$ and $(\varepsilon)$ implies $(\eta)$, then $(\beta)$ implies that it could still turn out that God was mistaken about or in ignorance of whether you'll eat cake tonight - which I take to imply that there isn't an omniscient God. So the Thomasonian egalitarian who wants to oppose our main argument will have to say resist either the inference from $(\gamma)$ to $(\delta)$ or the inference from $(\varepsilon)$ to $(\eta)$. Since (I take it) those inferences stand or fall together, the Thomasonian will have to resist both.

So it looks as though (in resisting the inference from $(\gamma)$ to $(\delta)$ ) the (openness-acknowledging) Thomasonian egalitarian will still have to take issue with premiss (5), despite already having taken issue with (2). Like the privilegist, he must either say that God is at no risk of error now, even though what $\mathrm{He}$ in fact now believes about the open future is now at risk of falsity (!) - or take Boethius's way out, and say that currently contingent propositions are at risk of falsity in our nunc fluens, but God is not at risk of error in His nunc stans.

\section{CONCLUSION}

Exclusivism appears to be a live option. If exclusivism is true, there is no immediately obvious reason to think exclusivist privilegism, rather than exclusivist egalitarianism is true. If exclusivist egalitarianism is true, then premiss (2) of our main argument is false. So it's natural to wonder whether we would do better defending the reality of an omniscient God and an open future in the face of the main argument if we challenged that argument's second premiss, rather than conceding that premiss and challenging its fifth premiss instead. If I'm right, we wouldn't. Although there are no immediately obvious reasons to prefer exclusivist privilegism to exclusivist egalitarianism, I have argued that there are not immediately obvious reasons for doing so. Different varieties of egalitarianism encounter different problems, but it looks as though none of them are problem-free. Assuming that there is no privileged (complete) history, egalitarians working out a systematic account of truth and (historical) necessity seem to face a whole series of hard choices: should (historically) 
contingent propositions be false, or indeterminate? Should disjunctions and conjunctions be thought of as determined exclusively by the truthvalues of their disjuncts/conjuncts, or not? And so on. Even though some ways of answering these questions seem better than others, I am unaware of any entirely satisfactory way of answering them. (For instance, Peircean egalitarianism, unlike the Lukasiewiczian or Thomasonian kind, has the virtue of allowing us to accept both strong non-contradiction, and the unfalsity-preservingness of premiss-conjunction; but it has the vice of not leaving room for the idea that futurity, unlike inevitability, distributes over a disjunction (since, for Peircean egalitarians, futurity implies inevitability)). ${ }^{11}$ The contrast with privilegism is dramatic: assuming that the idea of a privileged history makes sense, the privilegist doesn't seem to face any hard choices in working out a systematic account of truth and (historical) necessity. This contrast is due to the fact that a privilegist with a worked out account of truth-at-a-time-ina-possible-history already has a worked out account of truth at a time (truth at a time is just a special case of truth-at-a-time-in-a-possiblehistory (viz., truth-at-a-time-in-the-privileged-history)). The egalitarian with a worked out account of truth-at-time-in-a-possible-history faces all sorts of additional and difficult questions about the relation between truth-at-a-time-in-a-possible-history and truth at a time. Finally - and crucially - egalitarianism as such does not accommodate our reluctance to flatly assert it's not true that $p$ when we think it's open whether $p$.

There is another reason to doubt that we would be better placed to defend the openness of the future and the omniscience of God in the face of the main argument if we embraced egalitarianism, rather than privilegism. Both the Peircean and the Lukasiewiczian versions of egalitarianism have consequences that are extremely difficult to accept. Of the versions of egalitarianism I am familiar with, the one that seems least hard to accept is the Thomasonian one. And (I have tried to show) Thomasonian egalitarians are no better placed than privilegists to defend the openness of the future and the existence of an omniscient God, in the face of the main argument, since Thomasonian egalitarians who want to resist the argument, just like privilegists who do, will have to challenge

${ }^{11}$ To say that inevitability "distributes over disjunction" is to say that it inevitable that: $p$ or $q$ implies it is inevitable that $p$ or it is inevitable that $q$. To say that futurity distributes over a disjunction is to say that it will be that: $p$ or $q$ implies it will be that $p$ or it will be that $q$. 
the sort of "possibility-exporting" inference that takes us from God accepts that $p$ and it is (still) possible that it's not the case that $p$ to it's (still) possible that: God accepts that p, but it's not the case that p. So, it seems, will the champions of any variety of egalitarianism that (plausibly enough) implies strong non-contradiction + strong excluded middle, and implies that whenever it's open that $p$, it is inevitably open that $p$.

So, after all that, how should we respond to the argument set out at the beginning of this paper? Following Occam, we can challenge the "possibility-exporting" inference from God accepts that $p$ and it is (still) possible that $p$ to it's still possible that: God accepts that p, but it's not the case that $p$. Otherwise - unless (like Richard Swinburne) we think there are truths beyond even the ken of omniscient being (so that premiss (11) is false) - our only remaining option appears to be saying (along with Jonathan Edwards) that the argument is sound, and compels those of us who would want to believe in an omniscient God and an open future to give up one or the other. ${ }^{12}$

${ }^{12}$ As readers hardy enough to have won through to the end of this paper may already have gathered, this paper has been growing a long time. Previous versions of (proper or improper parts of) this paper have been read to audiences at Oxford, Trinity College Dublin, and the universities of Genova, Milano (Statale), San Raffaele, Bergamo, and Padova. Special thanks to Peter van Inwagen, Richard Swinburne, Brian Leftow, Nicla Vassallo, Andrea Bottani, and Massimiliano Carrara, and to Rosa Maria Antognazza, who encouraged and probabilified the publication of this piece. Gratitude is also owed to students and colleagues at King's and Notre Dame for fruitful discussions of ideas that ended up in these pages. 